\title{
Study on the wave dissipation properties of the no bottom semi-circular
}

\section{wave dissipation block}

\author{
Tao $\mathrm{Yu}^{1, \mathrm{a}}, \mathrm{Zi-chang}$ Shang-guan ${ }^{1, \mathrm{~b}}$, Yu-long Wang ${ }^{1, \mathrm{c}}$, \\ Lu Shen $^{1, d}$,Yu-hang Liu ${ }^{1, e}$, and Jing Zhang ${ }^{2, f}$ \\ 1 Dalian Ocean University, Dalian 116023,China \\ 2 Dalian Port Design and Research Institute Co, Dalian 116021,China \\ a1039392991@qq.com, bshangguan@dlou.edu.cn, ${ }^{c} 1017910091 @ q q . c o m$, \\ dshenlu@dlou.edu.cn, ${ }^{e} 735868870 @ q q . c o m,{ }^{\prime} 804959861 @ q q . c o m$
}

Keywords: no bottom; semi-circular wave dissipation block; transmission coefficient; wave dissipation effect;

Abstract. This paper through a lot of physical model tests. Studied no bottom semi-circular wave dissipation block under the action of waves and transmission coefficients. It analyzes the impact of no bottom semi-circular wave dissipation block in different structures, different arrangement and other aspect of wave dissipation effect.

\section{Introduction}

Coastal erosion is a common geological disasters, China is one of the world's most suffering from this disaster-hit countries. China's coastline is 18000 kilometers, gravel Coast accounted for over $30 \%$, of which $70 \%$ gravel Coast there are coastal erosion phenomena, such as Wenchang County, Hainan Province, due to the coral reefs being mined, the coast has been back more than 200 meters. Coastal erosion caused by loss of land resources, water washed away to the human habitat, serious impact on coastal areas of economic and social development. Therefore, the protection of the coast is particularly important, a variety of breakwaters have been applied to the project. The semi-circular breakwater as a new type of breakwater, and has the advantages of good stability, low cost, convenient construction, after placing can resist waves hit and appearance is beautiful, and advantages. No bottom structure due to its light weight, prefabrication process is simple and also more and more get the attention of engineering.

Xie Shileng etc. [1] semi-circular breakwater dike after wave height is analyzed, it is pointed out that the Japanese semi-circular breakwater design manual calculation of transmission coefficient $\mathrm{Kt}$ and reflection coefficient $\mathrm{Kr}$ chart only applies to the breakwater crest above the horizontal plane of the case. Meanwhile Xie Shileng [2-7] through physical model tests, it is pointed out that the Japanese general Goda correction wave pressure formula under the condition of submerged breakwater will be unsafe results. Guo Ke etc. [8-12] through a large number of model test study, analyzed the semi-circular breakwater under wave action stability, reflection and transmission coefficients and the stress situation, carries on the preliminary discussion of the new structure. The current domestic research on no bottom in the form of a little. This paper mainly studies the impact of no bottom semi-circular wave dissipation block wave dissipation effect. Through the physical 
model tests, the factors of the structure under different wave, different structures, different experimental study arrangement, etc.

\section{Model test}

Test equipment. Tests carried out in Liaoning Province Dalian Ocean University Key Laboratory of Coastal Engineering wave flume (total length $40 \mathrm{~m}$, width $0.7 \mathrm{~m}$, height $1 \mathrm{~m}$ ). At the end of the water flume is equipped with a wave machine, can produce a one-way regular wave, irregular wave, and the wave is stable and good repeatability. At the other end of the water flume is equipped with wave dissipation device, used to dissipate the wave energy to reduce the wave reflection. Wave machine is controlled by the microcomputer system and automatic data collection and analysis of test data. The wave is measured using DS30 type 64 channel wave height recorder (3) The sensitivity and stability requirements of these instruments and equipments in the test and after the test were carried out to provide the necessary guarantee for the successful physical model test.

Test wave elements. Test for regular waves, (according to the Liaoning Yingkou Bayuquan wave observation station of historical data to determine the actual wave elements), and then considering conditions of test equipment, wave machine can produce the maximum wave height and to ensure that such factors are not broken, and in accordance with the gravity similarity criterion to determine

test wave elements. Test water depth $d=0.30 \mathrm{~m}$ and $\mathrm{d}=0.40 \mathrm{~m}$, respectively using three groups of wave height of $0.07 \mathrm{~m}, 0.08 \mathrm{~m}, 0.09 \mathrm{~m}$, wave period were $0.8 \mathrm{~s}, 0.9 \mathrm{~s}, 1.0 \mathrm{~s}, 1.1 \mathrm{~s}$, respectively corresponding to the wavelength of $1.0 \mathrm{~m}, 1.26 \mathrm{~m}, 1.56 \mathrm{~m}, 1.89 \mathrm{~m}$, according to the model test of scale 1:30 to consider and respectively correspond to actual period of $4.38 \mathrm{~s}, 493 \mathrm{~s}, 5.48 \mathrm{~s}, 6.03 \mathrm{~s}$. Test wave elements in Table 1.

Table 1 Test wave elements

\begin{tabular}{cccccc}
\hline Water depth $(\mathrm{m})$ & Wave height $(\mathrm{m})$ & \multicolumn{5}{l}{ Wave cycle (s) } \\
& & & & & \\
\hline 0.30 & 0.07 & 0.80 & 0.90 & 1.00 & 1.10 \\
0.30 & 0.08 & 0.80 & 0.90 & 1.00 & 1.10 \\
0.30 & 0.09 & 0.80 & 0.90 & 1.00 & 1.10 \\
0.40 & 0.07 & 0.80 & 0.90 & 1.00 & 1.10 \\
0.40 & 0.08 & 0.80 & 0.90 & 1.00 & 1.10 \\
0.40 & 0.09 & 0.80 & 0.90 & 1.00 & 1.10 \\
\hline
\end{tabular}

Test model design. No bottom semi-circular wave dissipation block with semi-circular breakwater prototype. Test model Scale 1:30, the outer radius of the circular are $225 \mathrm{~mm}$, an inner radius of 200 $\mathrm{mm}$, the structure thickness $25 \mathrm{~mm}$, width $680 \mathrm{~mm}$ (length $450 \mathrm{~mm}$, width $680 \mathrm{~mm}$, height $225 \mathrm{~mm}$ ) The flume model meets the similar geometry and flow pattern. Opening rate in the following table:

\begin{tabular}{|c|c|c|}
\hline Opening rate $(\%)$ & Hole diameter $(\mathrm{mm})$ & Open hole number \\
\hline 0 & 0 & 0 \\
\hline \multirow{2}{*}{14.72} & 50 & 36 \\
\cline { 2 - 3 } & 75 & 16 \\
\hline
\end{tabular}

Model test arrangement. At the end of the water flume is equipped with a wave machine, at the 
other end of the water flume is equipped with wave dissipation device, the model is arranged in the middle of the water flume, the distance between wave machine $20 \mathrm{~m}$, as shown in figure 2. Dike arranged one wave height recorder, where \#1wave height recorder arranged in the front-end $2.0 \mathrm{~m}$ distance model, is the front-end acquisition model of incident waves wave height; Dike arranged after a wave height recorder, \#2wave height recorder arranged in the back-end $1.8 \mathrm{~m}$ distance model, is used to measure the transmission wave height. Each test is repeated three times and averaged.

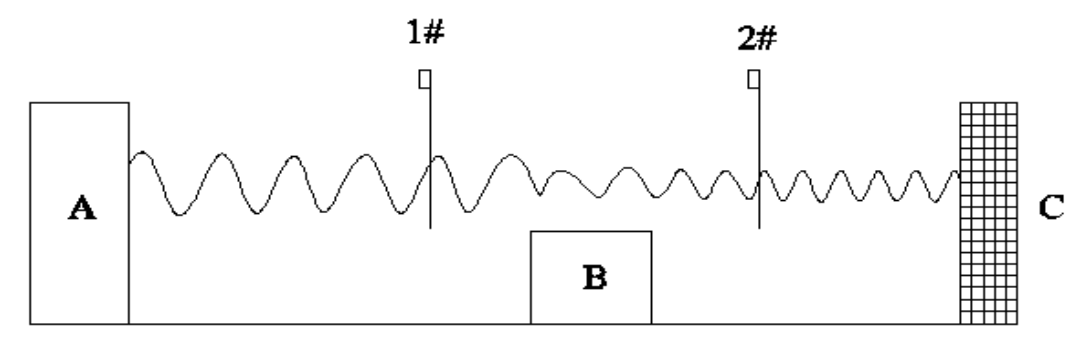

A: Wave machine B:Model C:Wave dissipation device \#1 \#2: Wave height recorder

Figure 2: Model test layout

\section{Test Results and Analysis}

Rows different arrangement for no bottom semi-circular wave dissipation block wave dissipation effect. Test selection model hole diameter $0 \mathrm{~mm}$, the arrangement spacing of $0.3 \mathrm{~m}$, depth $0.3 \mathrm{~m}$, wave elements of $0.08 \mathrm{~m}$ wave height and period were $0.8 \mathrm{~s}, 0.9 \mathrm{~s}, 1.0 \mathrm{~s}, 1.1 \mathrm{~s}$, the selection of a row ,two rows, three rows, four rows test respectively. Test results are shown in Figure 1 as the abscissa period (s), the ordinate is the transmittance coefficient (\%);

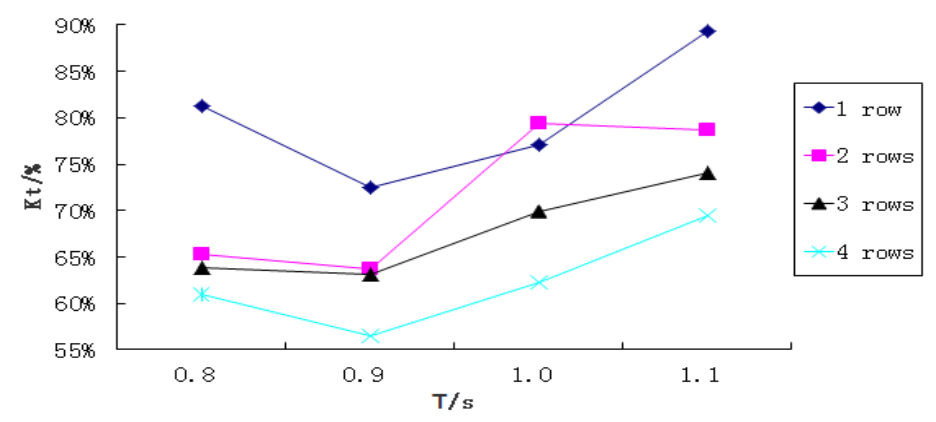

Figure1

Test result analysis: Under the same conditions, when arranged in a row by the row number gradually increased to four rows, the transmission coefficient of the change trend shown in Figure 1. Among when the number of rows is arranged in four rows, the transmission coefficient of the structure are maintained between $55 \%$ to $70 \%$, a smooth trend line chart, each point corresponding transmission coefficients are smaller than the other three cases, so the effect is better than the other three cases. Therefore when arranged in four rows works best when wave dissipation, wave dissipation performance is strong.

Holes in different forms of no bottom semi-circular wave dissipation block wave dissipation effect. Test selects the arrangement spacing of $0.3 \mathrm{~m}$, depth of $0.3 \mathrm{~m}$, arranged in four rows, wave element for wave height $0.07 \mathrm{~m}$ and $0.08 \mathrm{~m}, 0.09 \mathrm{~m}$ and cycle respectively $0.8 \mathrm{~s}, 0.9 \mathrm{~s}, \mathrm{~s} 1.0,1.1 \mathrm{~s}$, the selection of the model openings diameter of $0 \mathrm{~mm}, 50 \mathrm{~mm}$ and $75 \mathrm{~mm}$ hole form experiment, respectively. Test results as below 2.1, 2.2, 2.3 shows, figure 2.1, 2.2, 2.3 respectively represent the wave height of $0.07 \mathrm{~m}, 0.08 \mathrm{~m}, 0.09 \mathrm{~m}$ at the line chart, the abscissa for the period (s), the ordinate is the transmittance coefficient $(\%)$; 


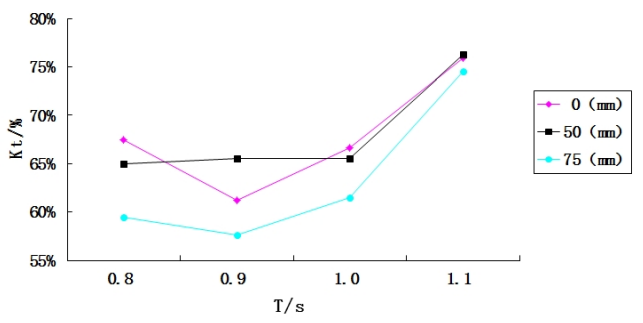

Figure 2.1

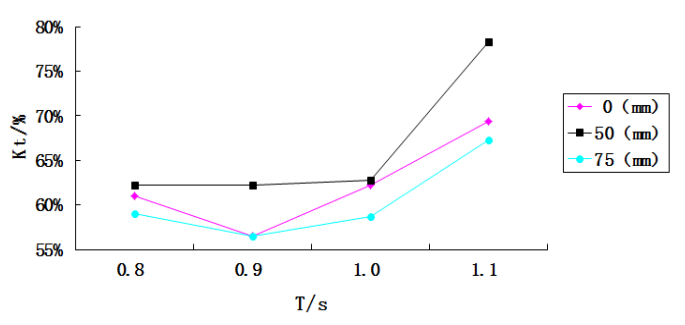

Figure 2.2

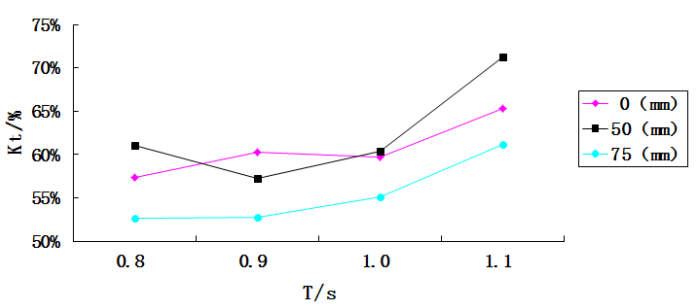

Figure 2.3

Test result analysis: Figure 2.1, 2.2, 2.3 can be obtained, when the wave height is constant, with the increase of cycle, the transmission coefficient is an increasing trend too. When the cycle is constant, different wave height, to obtain the transmission coefficient is different. From the above three figure is not difficult to see that, when the hole diameter is $75 \mathrm{~mm}$, the transmission coefficient of the three wave height are maintained between the $55 \% \sim 75 \%$, and wave dissipation effect is obvious, the performance of the wave is good. When the hole diameter is $0 \mathrm{~mm}$ and $50 \mathrm{~mm}$, respectively , the transmission coefficient little difference between the two, but the hole diameter is $50 \mathrm{~mm}$ when slightly better than $0 \mathrm{~mm}$. Therefore when the hole diameter is $75 \mathrm{~mm}$, wave dissipation effect model is relatively good. And a gradual increase in wave height as the transmission coefficient decreased.

\section{Layout spacing is different to no bottom semi-circular wave dissipation block wave dissipation} effect. Test selection depth $0.30 \mathrm{~m}$, arranged in four rows, the choice of model hole diameter of 75 mm wave elements of wave height and period when $0.09 \mathrm{~m}$ respectively $0.8 \mathrm{~s}, 0.9 \mathrm{~s}, 1.0 \mathrm{~s}, 1.1 \mathrm{~s}$, the arranged spacing were $0.00 \mathrm{~m}, 0.15 \mathrm{~m}, 0.30 \mathrm{~m}, 0.45 \mathrm{~m}, 0.60 \mathrm{~m}$ tested. Test results are shown in Figure 3 as the abscissa period (s), the ordinate is the transmittance coefficient (\%);

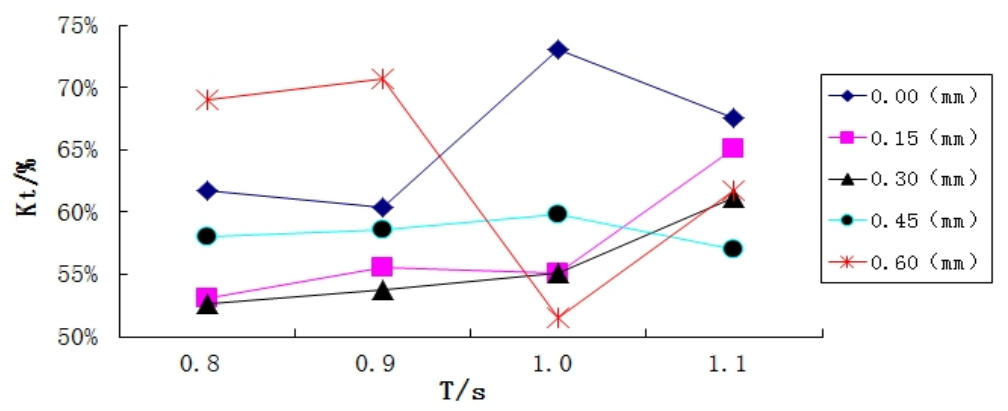

Figure 3

Test result analysis: Figure 3 can be obtained, when the arranged spacing was $0.30 \mathrm{~m}$, the transmission coefficient is smaller than the other four cases overall. In a period of $1.0 \mathrm{~s}$ when the arranged spacing is $0.60 \mathrm{~m}$ and a period of $1.1 \mathrm{~s}$ when arranged spacing $0.45 \mathrm{~m}$, the transmission coefficient is less than $0.30 \mathrm{~m}$. However, the two kinds of layout spacing in the rest of the period are more than the layout of the $0.30 \mathrm{~m}$, and the trend is not smooth. On the whole, when the spacing is 
$0.30 \mathrm{~m}$, the transmission coefficient is minimum, the variation range is minimum, and the most obvious effect wave dissipation.

Test the effect of different water depths for no bottom semi-circular wave dissipation block wave dissipation effect. Test selection model hole diameter $75 \mathrm{~mm}$, arranged spaced $0.30 \mathrm{~m}$, arranged in four rows, wave elements of $0.09 \mathrm{~m}$ wave height and period were $0.8 \mathrm{~s}, 0.9 \mathrm{~s}, 1.0 \mathrm{~s}, 1.1$ $\mathrm{s}$, the selection of a water depth of $0.30 \mathrm{~m}$ and $0.40 \mathrm{~m}$ were tested. Test results are shown in Figure 4 as the abscissa period (s), the ordinate is the transmittance coefficient (\%);

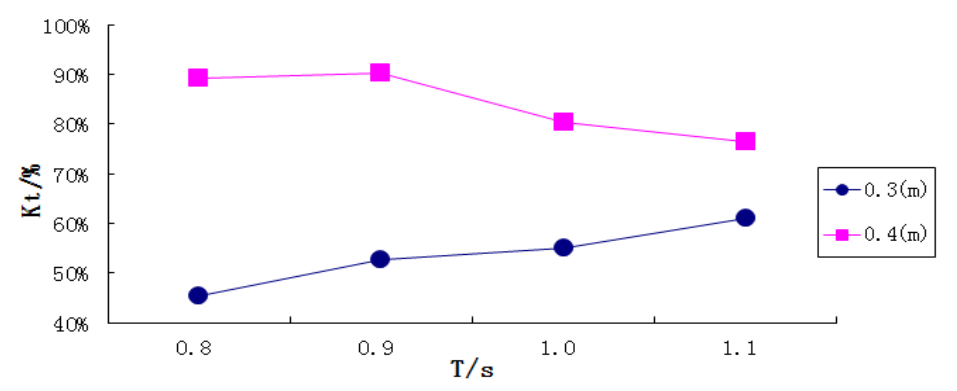

Figure 4

Test result analysis: Figure 4 can be obtained, when the test at $0.30 \mathrm{~m}$ depth, the transmission coefficient of structures remains between $45 \%$ to $65 \%$, the wave dissipation effect is more obvious, the performance of the wave is great; When the experiment at $0.40 \mathrm{~m}$ depth, the transmission coefficient of structures remain between $75 \%$ to $95 \%$, the wave dissipation effect is not obvious, the wave dissipation effect is poor.

\section{Conclusions}

(1) Under the same other factors, when arranged in a row by the row number gradually increased to four rows, the corresponding transmission coefficient decreases, the performance of the wave dissipation have enhanced.

(2)Under other factors and the opening rate $(14.72 \%)$ the same conditions, to open a large hole $(75 \mathrm{~mm})$ in the transmission coefficient is less than the open holes $(50 \mathrm{~mm})$; Opening a large hole $(75 \mathrm{~mm})$ in the wave dissipation effect is better than the open holes $(50 \mathrm{~mm})$.

(3)Under other factors the same conditions, when arranged spacing of $0.30 \mathrm{~m}$, the transmission coefficient is relatively small, and relatively stable, the wave dissipation performance is better than the other four are arranged spacing.

(4)Under other factors the same conditions, the transmission coefficient when the test at $0.30 \mathrm{~m}$ depth is less than the overall test depth $0.40 \mathrm{~m}$;So the wave dissipation performance of the model is better than that of $0.30 \mathrm{~m}$ when the water depth is $0.40 \mathrm{~m}$.

\section{Reference}

[1]Xie Shileng, Cai Yanjun, 1999. Analysis of the wave heights behind submerged semi-circular breakwater, Port Engineering Technology, 04:1-3. (in Chinese)

[2]Xie Shileng, 1998. Submerged semi-circular case guided wave force on the embankment, Port Engineering Technology,02:1-5. (in Chinese) 
[3]K . Tanimoto and S. Takahashi, 1994 . Japanese Experienees on Composite Breakwaters , Proc . Intern . Workshop on"Wave Barriers in Deepwaters".

[4]H . Sasajimaetal,1994 . Field Demonstration Test on a Semi-circular Breakwater , proc . Intern . Conference on Hydro-Technical Engrg . for Port and Harbor Construction.

[5]Dalian University of Technology,1996. The mouth of the Yangtze River embankment project guide semi-circular breakwater on the hydraulic model test report. (in Chinese)

[6]Japan transport fourth Harbour Construction Bureau, Heisei 5 years. The development of semi-circular breakwater.

[7]Jia Donghua,1997. Study on the interaction between waves and semi-circular breakwater under different water level. The eighth national coastal engineering academic discussion paper on both sides of the Strait of port and coastal development seminar cum 1997 (lower parts), Beijing. Ocean Press. (in Chinese)

[8]Guo Ke, Li Meiying, 2000. Experimental study on semi-circular breakwater, China Harbour Construction, 06:27-30. (in Chinese)

[9]Tianjin Harbour Engineering Research Institute, 1998. The South guide model test report Di semi-circular cross-section. (in Chinese)

[10]Tianjin Harbour Engineering Research Institute, 1998. The North guide model test report Di semi-circular cross-section. (in Chinese)

[11]Tianjin Harbour Engineering Research Institute, 1998. Stability and wave force test report of long strip hole semi-circular breakwater . (in Chinese)

[12]Tianjin Harbour Engineering Research Institute, 1999. Test report of section model of semi-circular caisson scheme. (in Chinese) 